Acta vet. scand. $1984,25,327-332$.

From the Department of Surgery, College of Veterinary Medicine, Helsinki, Finland.

\title{
EVALUATING THE ACCURACY OF CANINE PREGNANCY DIAGNOSIS AND LITTER SIZE USING REAL-TIME ULTRASOUND
}

\author{
By \\ S. Bondestam, M. Kärkkäinen, I. Alitalo and M. Forss
}

BONDESTAM, S., M. KÄRKKÄINEN, I. ALITALO and M. FORSS: Evaluating the accuracy of canine pregnancy diagnosis and litter size using real-time ultrasound. Acta vet. scand. 1984, 25, 327-332. - A total of 135 bitches suspected of being pregnant were examined with a real-time ultrasound equipment. 58 bitches were not pregnant. In pregnancy diagnosis ultrasound produced an overall accuracy of $99.3 \%$, sensitivity $98.7 \%$, and specificity $100.0 \%$. Estimation of the litter size was fairly reliable in small litters of $1-3$ puppies.

ultrasonics; dogs; bitches.

Early detection of canine pregnancy is often desirable to evaluate proper care or medical treatment of the bitch and her delivery. Accurate diagnosis using conventional methods is, however, difficult or impossible. Abdominal and uterine findings may be misleading due to pseudo-pregnancy (Hancock \& Rowlands 1949). Radiography is not reliable until after the sixth week of gestation.

The Doppler ultrasound method can detect fetal heart activity and has to some extent been used in animal pregnancy diagnosis (Helper 1970, Weiss \& Ruckstuhl 1974, Preu 1975). This method has, however, a high rate of false positive findings (Lamm 1970). The A-mode ultrasound has been recommended as a rapid way of pregnancy testing in the sow and the bitch (Coffman 1972, Smith \& Kirk 1975).

Real-time ultrasound has routinely been used in human obstetrics as a safe and a reliable diagnostic tool which has now 
been adapted for use in veterinary medicine (Miller et al. 1981). This method has proved useful as a pregnancy test in laboratory rabbits (Cubberley et al. 1982) and in the dog (Bondestam et al. 1983).

The present study was carried out in order to estimate the accuracy of real-time ultrasound in detecting pregnancy and in counting the foetuses in the bitch.

\section{MATERIAL AND METHODS}

The study involved 145 out-patient bitches suspected of being pregnant. The material was collected over a period of 1 year beginning in May 1982. The first 8 bitches were excluded as they formed the material in the pilot study (Bondestam et al. 1983). Further 2 bitches were excluded; in one diagnosis verification was not obtained, in the other the examination was preceded by laparotomy. Thus the final material consisted of 135 bitches. Fifteen of the bitches had been artificially inseminated, 3 had unknown matings and the remaining 117 had been to service.

Based on the results achieved in the previous study, the earliest time chosen for examination was 28 days after the last insemination. The mean gestational age of the fetuses at the time of examination was 38.9 days. A portable real-time scanner (TOSHIBA SAL 22A) was used. The apparatus was equiped with a $2.4 \mathrm{MHz}$ linear array transducer.

The bitches were unsedated and there had been no restriction of food intake. The hair was not clipped. Voluminous transmission gel was used for good sonic coupling. Longhaired dogs, especially those with thick ground hair were scanned by carefully parting the hair. Most dogs were examined in lateral recumbency and, if necessary, they were calmed by their owners. Big dogs were scanned in the upright position. The abdomen was scanned thoroughly from the urinary bladder to the liver and both flanks in order to detect cystic structures with foetuses. The kidneys were sometimes seen but care was taken not to misinterpret them as foetuses. The detected foetuses were counted one by one. The results of the examination were verified by contact with the owner after the scheduled deliverytime. 


\section{RESULTS}

Fifty-eight bitches were not pregnant, all of which were correctly diagnosed by ultrasound. One case resulted in a false negative diagnosis as the only foetus was not detected; twentyone days later a badly maserated foetus was delivered. The sensitivity of detecting pregnancy was $98.7 \%$ (76 out of 77) specificity $100.0 \%$ (58 out of 58 ) and overall accuracy $99.3 \%$ (Table 1).

Ta b l e 1. Sensitivity and specificity in evaluation of pregnancy.

\begin{tabular}{lrrr}
\hline & & \multicolumn{3}{c}{ Pregnant } \\
& + & - \\
\hline \multirow{2}{*}{ Test } & + & 76 & 0 \\
\hline Total & - & 1 & 58 \\
\hline
\end{tabular}

Sensitivity: 76 out of $77=98.7 \%$

Specificity: 58 out of $58=100 \%$

Overall accuracy: 134 out out of $135=99.3 \%$

Litter size estimation resulted in over-estimation in cases of small litters and under-estimation in large litters (Table 2). The mean litter size was 5.4. The estimated mean litter size was 5.0.

T a b le 2. Estimated litter size compared to true size $(n=135)$.

\begin{tabular}{|c|c|c|c|c|c|c|c|c|c|}
\hline \multirow{2}{*}{$\begin{array}{l}\text { True litter } \\
\text { size (a) }\end{array}$} & \multirow{2}{*}{$\begin{array}{c}\text { Number of } \\
\text { litters }\end{array}$} & \multicolumn{7}{|c|}{ Estimated litter size (a+一pups) } & \multirow{2}{*}{$\begin{array}{c}\text { Accuracy } \\
\%\end{array}$} \\
\hline & & $\mathrm{a}-4$ & $a-3$ & $\mathrm{a}-\mathbf{2}$ & $a-1$ & $\mathbf{a}$ & $a+1$ & $\overline{a+2}$ & \\
\hline 0 & 58 & & & & & 58 & & & 100.0 \\
\hline 1 & 6 & & & & 1 & 5 & & & 83.3 \\
\hline 2 & 5 & & & & & 3 & 2 & & 60.0 \\
\hline 3 & 9 & & & & & 4 & 3 & 2 & 44.4 \\
\hline 4 & 11 & & & & 2 & 3 & 3 & 3 & 27.3 \\
\hline 5 & 9 & & & & 1 & 5 & 2 & & 55.5 \\
\hline 6 & 12 & & 1 & & 4 & 4 & 2 & 1 & 33.3 \\
\hline 7 & 10 & & & 2 & & 8 & & & 80.0 \\
\hline 8 & 7 & & & 2 & 3 & 2 & & & 28.6 \\
\hline 9 & 4 & & 1 & 2 & 1 & & & & 0.0 \\
\hline 10 & 2 & 1 & 1 & & & & & & 0.0 \\
\hline 14 & 1 & 1 & & & & & & & 0.0 \\
\hline $16^{\star}$ & 1 & & & & & & & & 0.0 \\
\hline
\end{tabular}

* estimated only 7 foetuses. 
The likelihood of error in estimating the litter size was calculated by using the figures from the material. The confidence limits for the maximum likelihood of error were obtained from binomial distribution tables. The accuracy range was adjusted due to the nature of the study; +-0 foetus when the litter size was -3 puppies. When the true litter size was $4-8$ puppies the accuracy range of estimation was adjusted to true litter size +-1 foetus. In litters of -3 puppies the error percentage was $0-55.6$ (mean 28.1). In litters of $4-8$ puppies the error percentage ranged from 11.1 to 28.6 (accuracy range +-1 foetus). The error percentage was not estimated in litters of more than 8 puppies as the underestimation was remarkable.

The accuracy of litter size estimation increased with the advance of pregnancy (Table 3 ).

T a b l e 3. Accuracy of litter size estimation in relation to duration of pregnancy (accuracy range +-1 foetus).

\begin{tabular}{lccc}
\hline $\begin{array}{l}\text { Days since } \\
\text { last mating }\end{array}$ & $\begin{array}{c}\text { Number of } \\
\text { pregnant bitches }\end{array}$ & $\begin{array}{c}\text { Number of correctly } \\
\text { estimated litter sizes }\end{array}$ & $\begin{array}{c}\text { Accuracy } \\
\%\end{array}$ \\
\hline-29 & 5 & 5 & 40.0 \\
$30-39$ & 50 & 38 & 76.0 \\
$40-49$ & 16 & 13 & 81.3 \\
$50-$ & 6 & 5 & 83.3 \\
\hline Total & 77 & 58 & 75.3 \\
\hline
\end{tabular}

\section{DISCUSSION}

In the present study, the accuracy of real-time ultrasound in the detection of canine pregnancy and foetal count was evaluated. In pregnancy diagnosis, real-time utrasound resulted in an overall accuracy of $99.3 \%$. The sensitivity was $98.7 \%$ and specificity 100. $\%$.

Computed from the results presented by Lamm (1970), the corresponding values with Doppler ultrasound are accuracy $84.6 \%$, sensitivity $100 \%$ and specifity $67.7 \%$. It seems that with the Doppler ultrasound the specificity is low, which means that there are many false positive findings. By using real-time ultrasound false positive findings may be avoided. One false negative finding was reported in the present study. In this particular case the only foetus was very likely dead at the moment of the examination as 21 days later a badly maserated foetus was 
born. Probably lack of foetal fluid and foetal activity resulted in this negative diagnosis.

The estimation of litter size is not as important as the pregnancy diagnosis. However, breeders are anxious to know if there is a small litter coming which in some cases may cause a troublesome delivery. Foetal count can be estimated by radiography in late pregnancy but no reports on its accuracy are available. It seems possible that some foetuses may become undetected if they jerk during the radiographic exposure. The use of ultrasound makes it possible to undertake the examination about 1 month earlier than by radiographical methods.

In the present study, 6 single-pup litters were found. Of those 1 was reported as not pregnant, i.e. the false negative diagnosis mentioned above. The other 5 were correctly diagnosed. Overestimation dominated in small litters. In the $\mathbf{5}$ twin litters $\mathbf{2}$ were over-estimated as 3-pup litters. Naturally, underestimation was common in large litters and the error percentage was high. However, up to 5-pup litters a discrepancy of more than 2 foetuses did not occur.

It seems that real-time ultrasound is a very reliable pregnancy test. It may be used as soon as 4 weeks after conception, it is easy to use, and compared to radiography the apparatus is cheap and there is no radiation hazard. The equipment may be ambulatory. Only a linear probe was available. In this study there was some problem in the examination of thick-haired dogs with the probe. A sector scan probe would be more suitable.

According to the results of the present study, the litter size can be exactly estimated only in the case of small litters but an enhanced experience in this new field will, however, improve the accuracy.

\section{REFERENCES}

Bondestam, S., I. Alitalo \& M. Kärkkäinen: Real-time ultrasound diagnosis in the bitch. J. small Anim. Pract. 1983, 24, 145-151.

Colfman, B.: Fastest way yet to pregnancy test. Farm Journal 1972, December 25.

Cubberley, D. A., T. L. Leen, C. L. Laughlin, B. Weintraub, M. R. Caudle \& D. Van Nielson: Importance of ultrasound determination of pregnancy in the rabbit. Amer. J. vet. Res. 1982, 43, 1802-1803.

Hancock, J. L. \& I. W. Rowlands: The physiology of reproduction in the dog. Vet. Rec. $1949,61,771-776$. 
Helper, L. C.: Diagnosis of pregnancy in the bitch with an ultrasonic doppler instrument. J. Amer. vet. med. Ass. 1970, 156, $60-62$.

Lamm, A.-M.: Ultrasound diagnosis of pregnancy in the dog. Acta Radiol. 1970, 319, 293-294.

Miller, C. M., W. E. Wingfield \& J. A. Boon: Applications of ultrasound to veterinary diagnostics in a veterinary teaching hospital. Biomed. Sci. Instrum. 1981, 17, 85-90.

Preu, K. P.: Zur Trächtigkeitsdiagnose an der Hündin mittels Ultraschall. (Ultrasonic diagnosis of pregnancy in the bitch.) Kleintierpraxis $1975,20,173-204$.

Smith, D. M. \& G. R. Kirk: Detection of pregnancy in the dog. Small animal medicine in brief $1975,11,201-203$.

Weiss, G. \& B. Ruckstuhl: Möglichkeiten der Ultraschall-DopplerDiagnostik in Geburtshilfe und Gynäkologie bei Haustieren. (Possibilities of Doppler Ultrasound diagnosis in obstetrics and gynecology of domestic animals.) Prakt. Tierarzt 1974, 1, 6-8.

\section{SAMMANFATTNING}

Utvärdering av noggranheten vid diagnostisering av dräktighet och bestämmande av valpkullens storlek hos hund med real-tid ultraljud.

Sammanlagt 135 tikar, som antogs vara dräktiga, undersöktes med realtid-ultraljudapparatur. 58 tikar var icke dräktiga. Vid dräktighet uppnåddes i ultraljudsundersökningen en 99,3 procents noggrannhet, 98,7 procents sensitivitet och 100,0 procents specificitet. Estimering av kullstorleken var rätt pålitlig i små kullar med $1-3$ valpar.

(Received May 7, 1984).

Reprints may be requested from: M. Kärkkäinen, the Department of Surgery, College of Veterinary Medicine, Hämeentie 57, 00550 Helsinki 55, Finland. 